\title{
Demonstration of Hepatitis C Virus RNA with In Situ Hybridization Employing a Locked Nucleic Acid Probe in Humanized Liver of Infected Chimeric Mice and in Needle-Biopsied Human Liver
}

\author{
Kazuya Shiogama, ${ }^{1}$ Ken-ichi Inada, ${ }^{1}$ Michinori Kohara, ${ }^{2}$ Hidemi Teramoto, ${ }^{3}$ \\ Yasuyoshi Mizutani, ${ }^{1}$ Takanori Onouchi, ${ }^{1}$ and Yutaka Tsutsumi ${ }^{1}$ \\ ${ }^{1}$ Department of Pathology, Fujita Health University School of Medicine, Toyoake, Aichi 470-1192, Japan \\ ${ }^{2}$ Department of Microbiology and Cell Biology, Tokyo Metropolitan Institute of Medical Science, Tokyo 156-8506, Japan \\ ${ }^{3}$ Department of Internal Medicine, Kojin Hospital, Nagoya 463-8530, Japan
}

Correspondence should be addressed to Yutaka Tsutsumi; tsutsumi@fujita-hu.ac.jp

Received 30 December 2012; Revised 21 May 2013; Accepted 23 May 2013

Academic Editor: Hervé Lerat

Copyright (C) 2013 Kazuya Shiogama et al. This is an open access article distributed under the Creative Commons Attribution License, which permits unrestricted use, distribution, and reproduction in any medium, provided the original work is properly cited.

\begin{abstract}
Background. In situ hybridization (ISH) with high sensitivity has been requested to demonstrate hepatitis C virus (HCV) RNA in formalin-fixed, paraffin-embedded (FFPE) sections of the liver. Methods. ISH employing a locked-nucleic-acid- (LNA-)modified oligonucleotide probe and biotin-free catalyzed signal amplification system (CSAII) was applied to HCV-RNA detection in the liver tissue. Nested reverse-transcription polymerase chain reaction (RT-PCR) was performed for HCV genotyping using total RNA extracted from FFPE sections. The target tissues included FFPE tissue sections of humanized livers in HCV-infected chimeric mice (HCV genotypes 1a, 1b, and 2a and noninfected) and of needle-biopsied livers from HCV-infected patients. Results. HCV-RNA was demonstrated with the ISH technique in HCV-infected liver tissues from both chimeric mice and 9 (82\%) of 11 patients with HCV infection. The HCV signals were sensitive to RNase. Nested RT-PCR confirmed the genotype in 8 (73\%) of 11 livers (type $1 b$ : 6 lesions and type 2a: 2 lesions). HCV-RNA was not identified in chronic hepatitis B lesions, fatty liver, autoimmune hepatitis, and hepatocellular carcinoma. Conclusion. ISH using the LNA-modified oligonucleotide probe and CSAII was applicable to detecting HCV-RNA in routinely prepared FFPE liver specimens.
\end{abstract}

\section{Introduction}

Hepatitis C virus (HCV) is a single-stranded RNA virus, a member of the Flaviviridae family. Since the first identification of the HCV genome by Choo et al. [1], HCV study has progressed mainly in the field of HCV functional analysis and therapeutic implications. Because of low viral levels in the serum, the diagnosis of HCV infection has been made with a branched chain DNA signal amplification assay and reverse-transcription polymerase chain reaction (RT-PCR) [2-4]. The sensitivity of HCV detection in the serum thus became reproducible and clinically relevant.

Pathologists are often requested to detect viral pathogens within the routinely prepared biopsy tissue samples, and therefore simple and reliable histochemical techniques are needed. Techniques for visualizing HCV localization within diseased hepatocytes have also been developed. Reports have described the detection of HCV in human liver tissue by using immunohistochemistry and in situ hybridization (ISH) [414], as well as by in situ RT-PCR [4, 6, 15-20]. At the moment, $\mathrm{HCV}$ detection with immunohistochemistry and ISH is not yet reproducible enough, we believe. In situ RT-PCR may demonstrate highly sensitive signals, but with concomitant increase of false positivity. Reliable histochemical techniques for detecting $\mathrm{HCV}$ in formalin-fixed, paraffin-embedded (FFPE) liver tissues are needed, particularly for routine diagnostic purpose. 
In the present study, we established an ISH technique using a locked nucleic acid (LNA) probe and biotin-free tyramide amplification system (CSAII) for detecting HCVRNA in FFPE tissue sections of the liver.

\section{Materials and Methods}

2.1. Samples. As positive controls, we sampled the humanized liver of HCV-infected chimeric mice [21, 22], and FFPE tissue sections were prepared. The chimeric mice were maintained by M. Kohara, Department of Microbiology and Cell Biology, Tokyo Metropolitan Institute of Medical Science, Tokyo. A total of 13 humanized liver specimens from HCV-infected chimeric mice were used (noninfected 3, genotype la-infected 3 , genotype $1 \mathrm{~b}$-infected 4 , and genotype $2 \mathrm{a}$-infected 3 ).

A total of 11 needle biopsy liver specimens of chronic hepatitis $\mathrm{C}$ were culled from the computer file at the Diagnostic Pathology Division of Fujita Health University Hospital, Toyoake, Japan, and FFPE sections were cut. Needle biopsy specimens of hepatitis-B-virus- (HBV-)infected chronic hepatitis, virus-negative fatty liver and autoimmune hepatitis ( $n=1$, resp.), as well as two surgically removed HCC lesions caused by HCV or HBV infection, were also examined. The nonneoplastic part of the liver tissue (chronic hepatitis B) in the HBV-related HCC case was also evaluated. Nonneoplastic liver tissue was scarcely included in the HCVrelated HCC case. Hematoxylin and eosin (HE) staining was performed for demonstrating histological features. The activity of inflammation and the degree of fibrosis were evaluated according to the New Inuyama Classification (1996) [23]. Serum HCV-RNA levels in the patients were measured using an RT-PCR assay, the Amplicor HCV Monitor Assay (Roche Diagnostics), and serum HCV subtypes were determined with nested RT-PCR (Roche Diagnostics).

2.2. LNA-Modified Oligonucleotide Probe. The sequence of an $\mathrm{HCV}$-common probe was designed according to the previous description [15]. The target was within the HCV $5^{\prime}$-untranslated region ( $\left.\mathrm{HCV}-5^{\prime} \mathrm{UTR}\right)$, which is a highly conserved portion in the HCV genome. An LNA-modified oligonucleotide probe labeled with digoxygenin at the $3^{\prime}$ end was prepared in Gene Design Inc., Ibaraki, Osaka, Japan. The nucleotide sequence of the 45-mer probe was 5' -ALtTTLgGGLcGTLgCCLcCCLgCGLaGALcTGLcTALgCCLgAGLtAGLtGTLtGGLgT-3' ${ }^{\prime}$, in which La, Lt, Lc, and Lg represent LNA monomers corresponding to the bases A, T, $\mathrm{C}$, and $\mathrm{G}$, respectively.

2.3. ISH. FFPE sections were dewaxed in xylene and rehydrated in graded ethanol. Endogenous peroxidase activity was quenched with $0.3 \%$ hydrogen peroxide in methanol for 60 minutes at room temperature (RT). After rinsing thrice in diethyl-pyrocarbonate- (DEPC-)treated water, sections were digested with $40 \mu \mathrm{g} / \mathrm{mL}$ proteinase $\mathrm{K}$ (Roche Diagnostics, Tokyo, Japan) at $37^{\circ} \mathrm{C}$ for 15 minutes, washed thrice in DEPC-treated water, submerged in 95\% ethanol for 1 minute, and air-dried completely. Then, sections were heat-treated for 5 minutes at $95^{\circ} \mathrm{C}$ on a hot plate and hybridized with $0.01 \mu \mathrm{mol} / \mathrm{L}$ LNA-modified oligonucleotide probe diluted with in situ Hybridization Buffer (Enzo Life Science, Bulter Pike, PA, USA) in an incubation chamber overnight at $37^{\circ} \mathrm{C}$. After rinsing in $1 \mathrm{x}$ saline sodium citrate (SSC) for 30 minutes at $50^{\circ} \mathrm{C}$, sections were rinsed twice in $50 \mathrm{mM}$ Tris-HCl-buffered saline (TBS), pH 7.6, at RT. A horseradish-peroxidase-labeled antidigoxygenin antibody (Roche Diagnostics) diluted at 1:100 with 1\% bovine serum albumin in TBS was applied for 60 minutes at RT. For amplifying signals, fluorescein-isothiocyanate- (FITC-)conjugated tyramide enclosed in CSAII (Dako, Glostrup, Denmark) was applied to the sections for 15 minutes at RT. Finally, a horseradish-peroxidase-labeled anti-FITC antibody equipped in the CSAII kit was reacted for 30 minutes at RT. Reaction products were visualized in $50 \mathrm{mM}$ Tris- $\mathrm{HCl}$ buffer, $\mathrm{pH}$ 7.6, containing $20 \mathrm{mg} / \mathrm{dL}$ diaminobenzidine tetrahydrochloride and $0.006 \%$ hydrogen peroxidase. The nuclei were lightly counterstained with Mayer's hematoxylin.

In order to verify the specificity of the ISH technique for HCV-RNA detection, we carried out the treatment with DNase and RNase before the hybridization with the LNA probe on consecutive sections. Namely, either $10 \mathrm{IU} / \mathrm{mL}$ DNase I (Wako, Osaka, Japan) or $100 \mu \mathrm{g} / \mathrm{mL}$ RNase (SigmaAldrich, St. Louis, MO, USA) was incubated for 30 minutes at $37^{\circ} \mathrm{C}$.

\subsection{Immunostaining Using a Human Specific Cytokeratin 8/18} (CK8/18) Antibody. In order to distinguish mouse hepatocytes from chimeric human hepatocytes in $\mathrm{HCV}$-infected chimeric mice, we utilized a human-specific CK8/18 monoclonal antibody (clone: NCL 5D3, MP Biochemicals, Santa Ana, CA, USA). After blocking endogenous peroxidase activity, hydrated heat-assisted epitope retrieval was employed using a pressure pan cooker (Delicio 6L, T-FAL, Clichy, France) for 10 minutes. Preliminary study revealed that as a soaking solution, $1 \mathrm{mM}$ ethylenediamine tetraacetic acid solution, $\mathrm{pH}$ 8.0, was optimal to retrieve the antigenicity. After pressure cooking, sections were left for 30 minutes at RT for cooling. In order for avoiding nonspecific signals in mouse hepatocytes, a Mouse Stain kit (Nichirei Bioscience, Tokyo) was applied before and after the primary antibody incubation. The human-specific CK8/18 monoclonal antibody at a 1:100 dilution was incubated overnight at RT. After rinsing in $10 \mathrm{mM}$ phosphate-buffered saline (PBS), pH 7.2, the sections were reacted with a secondary polymer reagent, Novolink (Novocastra, Newcastle, UK). Reaction products were visualized in the diaminobenzidine-hydrogen peroxide solution. Nuclear counterstaining with hematoxylin followed.

2.5. HCV Genotyping by Nested RT-PCR. Five slices of $5 \mu \mathrm{m}$ thickness sections were collected in Eppendorf tubes. Total RNA was extracted from dewaxed sections using RecoverAll Total Nucleic Acid Isolation kit (Applied Biosytems, Austin, TX, USA), according to the manufacturer's protocol, and stored at $-80^{\circ} \mathrm{C}$ until use. Nested RT-PCR for HCV genotyping was performed, as described previously [24]. 
TABLE 1: HCV-RNA demonstration with LNA-based ISH and nested RT-PCR in FFPE human liver tissues.

\begin{tabular}{|c|c|c|c|c|c|c|c|}
\hline \multirow[b]{2}{*}{ Patient } & \multirow{2}{*}{$\begin{array}{l}\text { Biopsy or } \\
\text { surgery }\end{array}$} & \multirow{2}{*}{$\begin{array}{c}\text { Diagnosis } \\
\text { New Inuyama Classification }\end{array}$} & \multicolumn{2}{|c|}{ Serum } & \multicolumn{3}{|c|}{ FFPE liver tissue } \\
\hline & & & $\begin{array}{l}\text { HCV-RNA } \\
(\mathrm{KIU} / \mathrm{mL})\end{array}$ & $\begin{array}{l}\text { Nested } \\
\text { RT-PCR }\end{array}$ & $\begin{array}{l}\text { Nested } \\
\text { RT-PCR }\end{array}$ & & $\mathrm{H}$ \\
\hline Case 1 & $\mathrm{~B}$ & Chronic hepatitis $\mathrm{C}, \mathrm{A} 2 \mathrm{~F} 2$ & $5,1 \times 10^{2} \leqq$ & $1 \mathrm{~b}$ & $1 \mathrm{~b}$ & + & Focal/partial \\
\hline Case 2 & $\mathrm{~B}$ & Chronic hepatitis $\mathrm{C}, \mathrm{A} 1 \mathrm{~F} 1$ & $2,8 \times 10^{2}$ & $1 b$ & $1 b$ & + & Focal/partial \\
\hline Case 3 & $\mathrm{~B}$ & Chronic hepatitis C, A2,F1 & $2,4 \times 10^{2}$ & $2 \mathrm{a}$ & $2 \mathrm{a}$ & + & Diffuse \\
\hline Case 4 & $\mathrm{~B}$ & Chronic hepatitis C, A1F0 & $1,9 \times 10^{2}$ & $2 \mathrm{a}$ & $2 \mathrm{a}$ & - & \\
\hline Case 5 & $\mathrm{~B}$ & Chronic hepatitis C, A1F1 & $2,5 \times 10^{2}$ & $1 b$ & $1 b$ & + & Focal/partial \\
\hline Case 6 & $\mathrm{~B}$ & Chronic hepatitis $\mathrm{C}, \mathrm{A} 2 \mathrm{~F} 3$ & $2,7 \times 10^{2}$ & $1 b$ & - & - & \\
\hline Case 7 & $\mathrm{~B}$ & Chronic hepatitis C, A2F1 & $2,2 \times 10^{2}$ & $2 \mathrm{a}$ & - & + & Focal/partial \\
\hline Case 8 & $\mathrm{~B}$ & Chronic hepatitis $\mathrm{C}, \mathrm{A} 3 \mathrm{~F} 3$ & $5,1 \times 10^{2}$ & $1 b$ & $1 b$ & + & Focal/partial \\
\hline Case 9 & $\mathrm{~B}$ & Chronic hepatitis C, A2F1 & $2,9 \times 10^{2}$ & $1 b$ & $1 b$ & + & Diffuse \\
\hline Case 10 & $\mathrm{~B}$ & Chronic hepatitis C, A2F2 & $3,1 \times 10^{2}$ & $2 \mathrm{a}$ & - & + & Focal/partial \\
\hline Case 11 & $\mathrm{~B}$ & Chronic hepatitis C, A2F3 & $3,3 \times 10^{2}$ & $1 \mathrm{~b}$ & $1 \mathrm{~b}$ & + & Diffuse \\
\hline Case 12 & $\mathrm{~B}$ & Chronic hepatitis $\mathrm{B}, \mathrm{A} 3 \mathrm{~F} 3$ & Not detected & Not done & - & - & \\
\hline Case 13 & $\mathrm{~B}$ & Fatty liver, A0F0 & Not detected & Not done & - & - & \\
\hline Case 14 & $\mathrm{~B}$ & Autoimmune hepatitis, A3F3 & Not detected & Not done & - & - & \\
\hline Case 15 & S & $\begin{array}{l}\text { Hepatitis-B-related HCC } \\
\text { Chronic hepatitis B, A2F2 }\end{array}$ & Not detected & Not done & - & - & \\
\hline Case 16 & $\mathrm{~S}$ & Hepatitis-C-related HCC & 84 & Not done & - & - & \\
\hline
\end{tabular}

New Inuyama Classification (1996).

Activity of inflammation: A1: mild, A2: moderate, and A3: severe.

Fibrosis: F0: none, F1: portal widening, F2: bridging fibrosis, and F3: bridging fibrosis with lobular distortion.

2.6. Ethical Issue. The present study was approved by the institutional ethical review board for clinical and epidemiological investigations at Fujita Health University, Toyoake. The approval number is 12-193. Written informed consent was obtained from each patient.

\section{Results}

3.1. HCV-RNA Localization in Humanized Liver of HCVInfected Chimeric Mice. In HE-stained sections, mouse hepatocytes showed densely eosinophilic cytoplasm, while chimeric human hepatocytes were weakly eosinophilic with frequent deposition of fat droplets. Immunoreactivity of human CK8/18 was seen only in human hepatocytes. In all the $10 \mathrm{HCV}$-infected livers but not the livers of three HCV noninfected mice, ISH demonstrated diffuse cytoplasmic signals in the human hepatocytes. In Figure 1 employing consecutive sections, HCV-RNA was visualized with the ISH technique in human CK8/18-positive chimeric hepatocytes from chimeric mice infected HCV genotypes $1 \mathrm{a}, 1 \mathrm{~b}$, and $2 \mathrm{a}$ (in Figure 1, dotted lines encircle the mouse hepatocyte area). No signals were detected in the noninfected chimeric liver tissue. It is of note that HCV-RNA was demonstrated in the cytoplasm of almost all chimeric human hepatocytes. The positive signals remained after DNase treatment but were completely abolished after RNase treatment. Figure 2 illustrates HCV genotype $1 \mathrm{~b}$-infected chimeric mouse liver, showing HE histology and positive cytoplasmic signals, which were resistant to DNase but sensitive to RNase.
3.2. HCV-RNA Localization in Needle-Biopsied or Surgically Removed Human Liver Tissues. Results of the human material are summarized in Table 1 . Most of the HCV-positive patients showed high levels of HCV-RNA in the serum. Exceptionally, a surgical case of HCV-related HCC showed a low level of HCV-RNA in the serum. Nested RT-PCR genotyping for HCV using total RNA extracted from FFPE sections was successful in $8(73 \%)$ of 11 biopsied chronic hepatitis $\mathrm{C}$ lesions, and in all the 8 cases, the genotypes were comparable with the serum analysis. LNA-based ISH detected signals in 9 (82\%) of 11 chronic hepatitis C lesions, including three showing diffuse cytoplasmic positivity, and six showing focal or partial positivity. In three nested RTPCR negative lesions, ISH revealed negativity (1 lesion) or focal/partial positivity (2 lesions). One lesion was nested RTPCR-positive and ISH-negative. No HCV-RNA was detected in HBV-related lesions, fatty liver, autoimmune hepatitis, and in HCC lesions. Figure 3 demonstrates representative histochemical findings. Nonspecific binding of the CSAII reagent to Kupffer cells or lymphoid cells was occasionally observed in both the HCV-infected and HCV-unrelated lesions, as arrows indicate.

\section{Discussion}

We showed herein that LNA-based ISH for HCV-RNA yielded clear cytoplasmic reactivity in infected hepatocytes in FFPE sections. The LNA-modified oligonucleotide probe we employed represents one of the most sensitive probes for 


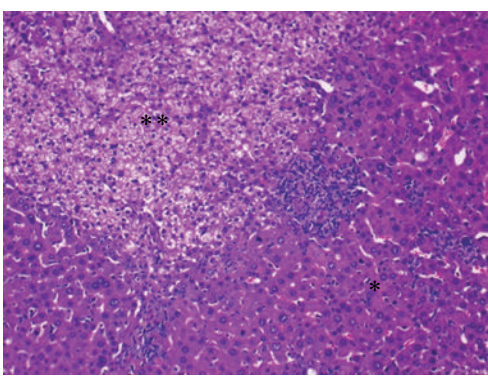

(a)

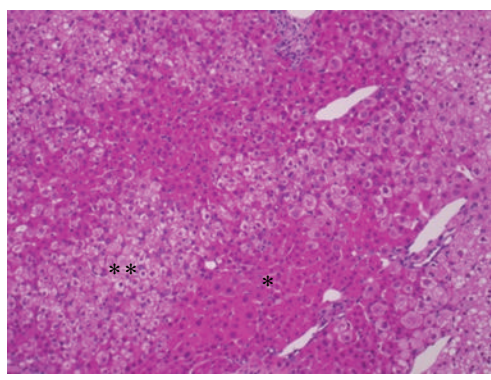

(d)

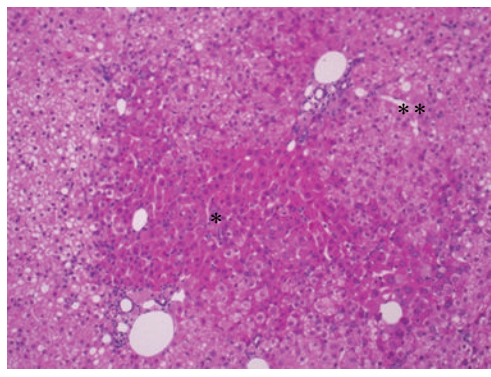

(g)

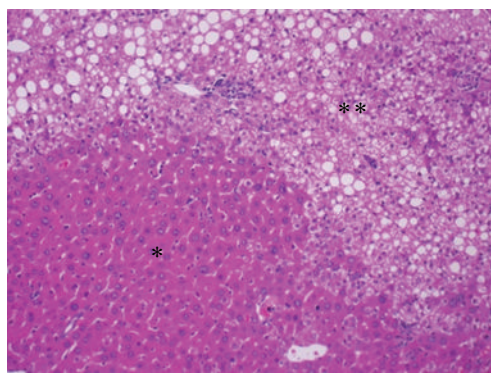

(j)

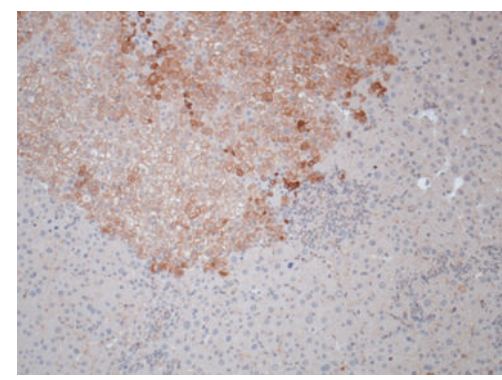

(b)

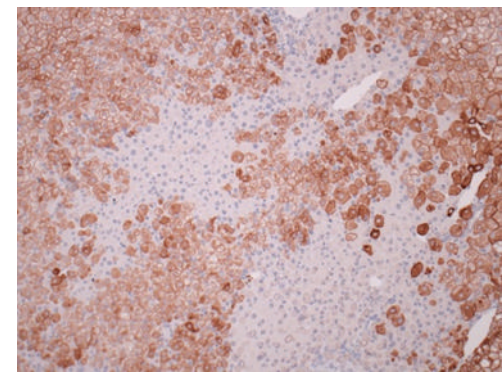

(e)

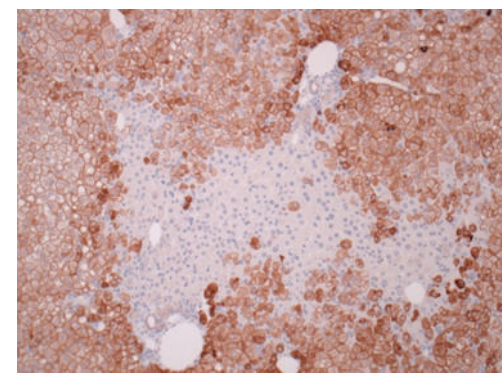

(h)

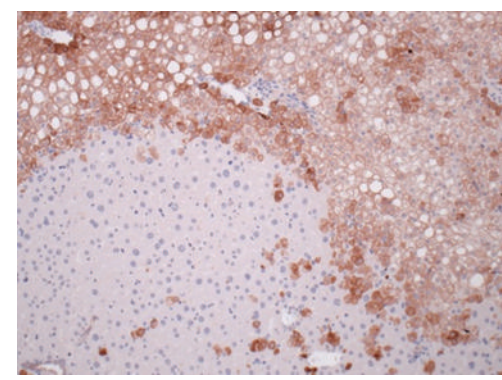

(k)

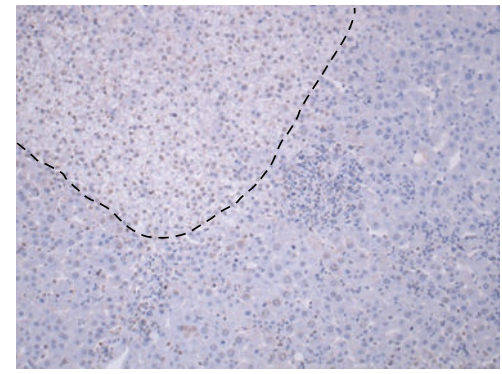

(c)

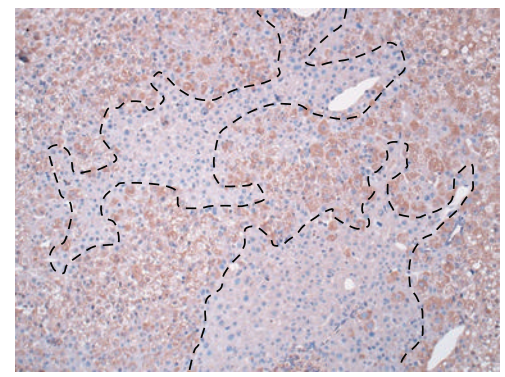

(f)

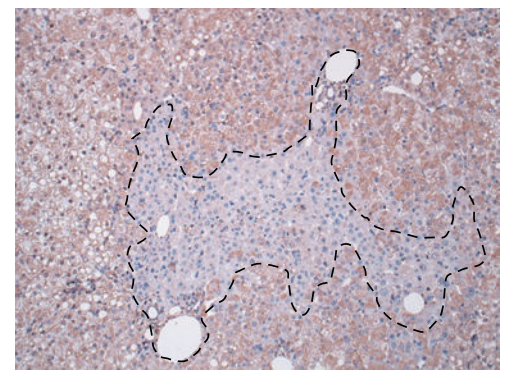

(i)

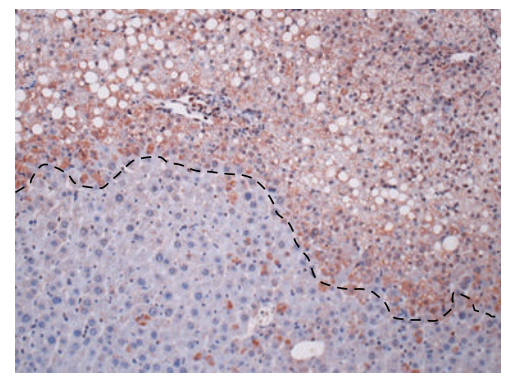

(l)

Figure 1: HCV-RNA localization with LNA-based ISH in the liver of chimeric mice infected with HCV of different genotypes. (a)-(c) HCV noninfected, (d)-(f) HCV genotype la-infected, (g)-(i) HCV genotype lb-infected, (j)-(l) HCV genotype 2a-infected, ((a), (d), (g), (j)) HE stain, ((b), (e), (h), (k)) immunostaining for human-specific CK8/18, ((c), (f), (i), (l)) LNA-based ISH, (*) mouse hepatocytes, and (**) human hepatocytes. HCV-RNA is demonstrated diffusely in the cytoplasm of human hepatocytes in the chimeric livers. No signals are seen in the noninfected liver.

ISH [25-29]. LNA-based ISH has been applied to detecting cellular microRNA in FFPE tumor tissues [30-32]. The 45mer LNA probe was targeted at the $\mathrm{HCV}-5^{\prime} \mathrm{UTR}$ containing a sequence common to the HCV subtypes. Positive signals for HCV-RNA were clearly demonstrated in HCV 1a-, 1b-, and $2 \mathrm{a}$-infected humanized livers of chimeric mice. HCVinfected chimeric mice with humanized liver thus functioned as a useful model for histochemically demonstrating the HCV genome, particularly when immunostaining for humanspecific CK8/18 was combined.

In needle-biopsied human liver specimens, HCV-RNA was detected in 8 of $11 \mathrm{HCV}$-infected samples with the nested RT-PCR analysis and in 9 of 11 with the ISH technique. In nested RT-PCR negative cases, ISH was negative or partially 


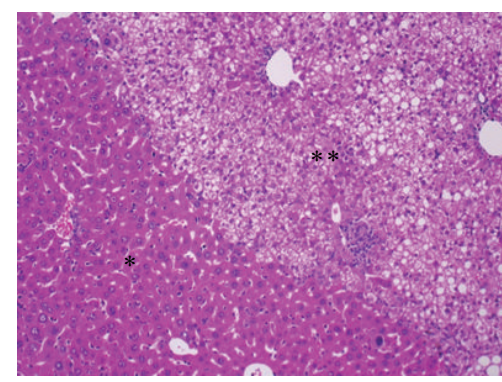

(a)

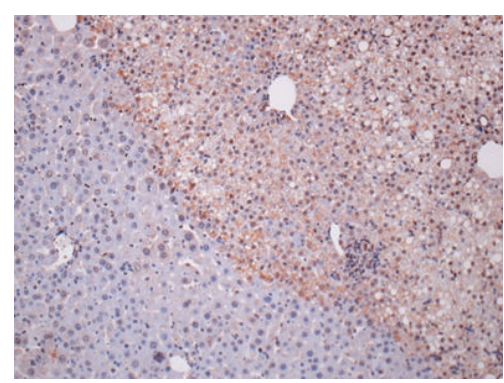

(b)

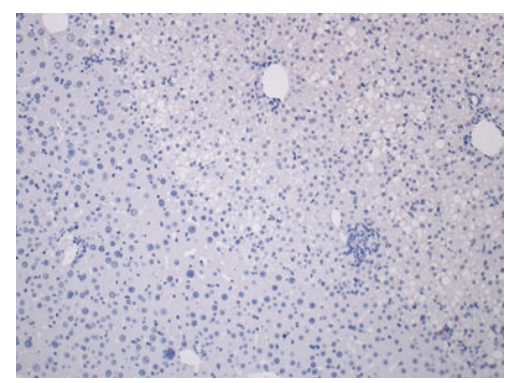

(c)

FIGURE 2: Confirmation of the specificity of LNA-based ISH. (a) HE stain, (b) ISH after DNase treatment, (c) ISH after RNase treatment, (*) mouse hepatocytes, and $(* *)$ human hepatocytes. The mouse hepatocytes are densely eosinophilic, while the human hepatocytes appear pale with deposition of fat droplets. HCV-RNA is observed only in the human hepatocytes in the chimeric liver infected with HCV genotype $1 \mathrm{~b}$. The HCV-RNA signals are resistant to DNase treatment but disappear after RNase treatment.

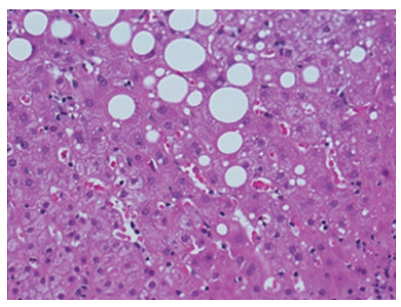

(a)

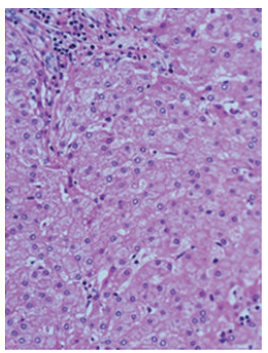

(e)

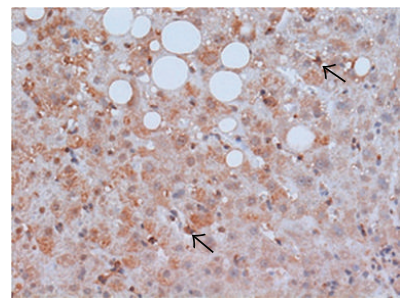

(b)

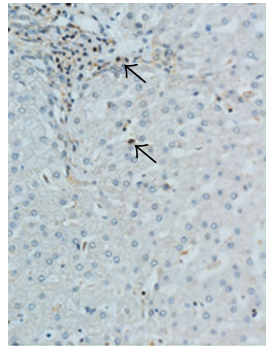

(f)

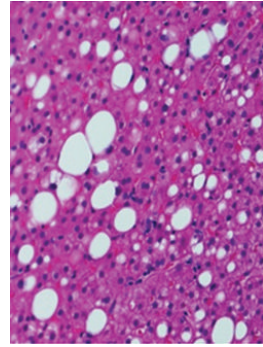

(g)

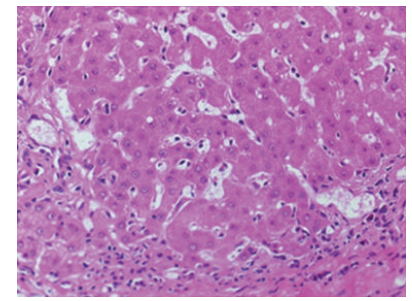

(c)

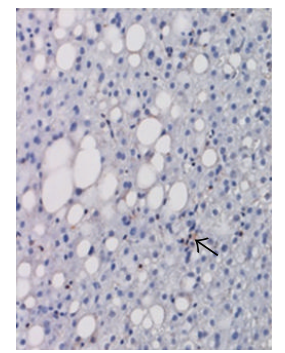

(h)

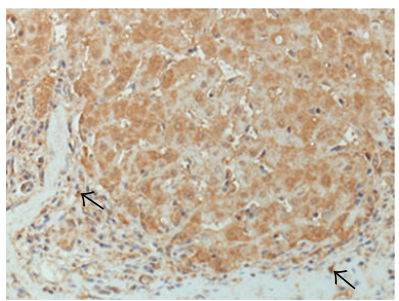

(d)

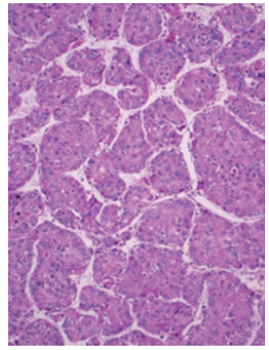

(i)

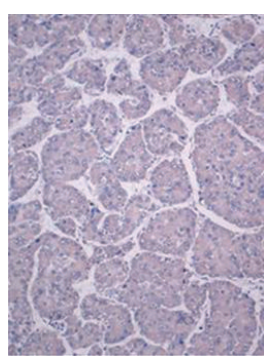

(j)

FIGURE 3: HCV-RNA localization with LNA-based ISH in FFPE biopsy or surgical specimens of the liver. ((a), (b)) Case 10 with chronic hepatitis C, ((c), (d)) case 11 with chronic hepatitis C, ((e), (f)) case 15 with chronic hepatitis B (noncancerous portion of a surgical case for HCC), ((g), (h)) case 13 with fatty liver, ((i), (j)) case 16 with surgically removed hepatitis-C-related HCC, ((a), (c), (e), (g), (i)) HE stain, and ((b), (d), (f), (h), (j)) LNA-based ISH. In HCV-infected human livers, the HCV-RNA signals are demonstrated in a focal/partial pattern (b) or in a diffuse pattern (d). Signals are not demonstrated in the hepatocytes of HBV-infected liver (f), fatty liver (h), and hepatitis-C-related HCC (j). Nonspecific binding of the reagent to Kupffer cells and lymphoid cells is occasionally observed (arrows in the panels (b), (d), (f), and $(\mathrm{h}))$.

positive, suggesting that the detection threshold may depend on the virus load. Diffuse HCV expression pattern in the hepatocytes was already reported by Nuriya et al. [15], Liang et al. [33], and Li et al. [34].

In the present ISH study, HCV-RNA was undetectable in the hepatocytes in HBV-infected livers, nonviral liver disorders (fatty liver and autoimmune hepatitis), and in HCV-related HCC. With ISH using a digoxygenin-labeled cDNA probe, Tang et al. reported positivity in $8(67 \%)$ of 12 HCV-related HCC [12]. It has been documented with an in situ RT-PCR technique that HCV-RNA decreases along with the progression from liver cirrhosis to HCC [35]. More cases of HCC need to be analyzed, in relation to the distribution of the HCV genome in cancerous lesions.

Revie and Salahuddin reviewed that HCV replicated in macrophages, $\mathrm{B}$ and $\mathrm{T}$ lymphocytes, and other nonhepatocellular components [36]. However, we judged the nonhepatocellular bindings as nonspecific reactions, primarily because of the staining in non-HCV cases. Under our present condition, nonspecific binding of the reagents, particularly CSAII, to Kupffer cells and lymphoid cells was observed. Further technical improvement is requested for reliable and reproducible HCV-RNA detection in FFPE specimens.

In conclusion, the ISH technique using the LNA-modified oligonucleotide probe and CSAII can be applied to detecting 
HCV-RNA in liver biopsy specimens, the sensitivity probably being comparable to in situ RT-PCR. For detecting the HCV genome in routinely prepared liver biopsy specimens, our ISH sequence is relatively simple and requires no special equipment to perform. At the moment, this method seems to be suitable for demonstrating HCV genome in FFPE sections and will become a valuable tool for routine histopathological diagnosis of HCV infection using FFPE liver biopsy specimens.

\section{Conflict of Interests}

The authors have no conflict of interests.

\section{Acknowledgments}

The authors thank Mr. Yutaka Hirasawa and Ms. Satomi Ito, Division of Diagnostic Pathology, Fujita Health University Hospital, for their cooperation in culling the specimens. Professor Kentaro Yoshioka, Department of Liver, Biliary Tract and Pancreas Diseases, and Professor Atsushi Sugioka, Department of Surgery, Fujita Health University School of Medicine, Toyoake, kindly allowed the authors to use the biopsy specimens. The skillful technical assistance by Ms. Mika Maeshima and Ms. Sayaka Takeuchi, Department of Pathology, Fujita Health University School of Medicine, is also cordially acknowledged. This work was in part supported by the Research Grant-in-Aid from the Japanese Ministry of Education, Culture, Sports, Science and Technology (no. 24790367).

\section{References}

[1] Q.-L. Choo, G. Kuo, A. J. Weiner, L. R. Overby, D. W. Bradley, and M. Houghton, "Isolation of a cDNA clone derived from a blood-borne non-A, non-B viral hepatitis genome," Science, vol. 244, no. 4902, pp. 359-362, 1989.

[2] A. M. Majid and D. R. Gretch, "Current and future hepatitis C virus diagnostic testing: problems and advancements," Microbes and Infection, vol. 4, no. 12, pp. 1227-1236, 2002.

[3] L. Muratori, "In situ reverse transcriptase-polymerase chain reaction: an innovative tool for hepatitis $\mathrm{C}$ virus RNA detection and localisation, and for quantification of infected cells," European Journal of Histochemistry, vol. 42, no. 2, pp. 133-136, 1998.

[4] P. Komminoth, V. Adams, A. A. Long et al., "Evaluation of methods for hepatitis C virus detection in archival liver biopsies. Comparison of histology, immunohistochemistry, insitu hybridization, reverse transcriptase polymerase chain reaction (RT-PCR) and in-situ RT-PCR," Pathology Research and Practice, vol. 190, no. 11, pp. 1017-1025, 1994.

[5] H. S. Carvalho, M. L. Baptista, M. A. Pinto et al., "Detection of hepatitis $\mathrm{C}$ virus RNA by in situ hybridization in paraformaldehyde fixed biopsies," Memorias do Instituto Oswaldo Cruz, vol. 100, no. 3, pp. 269-272, 2005.

[6] X. Qian, R. B. Guerrero, T. B. Plummer, V. F. Alves, and R. V. Lloyd, "Detection of hepatitis $\mathrm{C}$ virus RNA in formalin-fixed paraffin-embedded sections with digoxigenin-labeled cRNA probes," Diagnostic Molecular Pathology, vol. 13, no. 1, pp. 9-14, 2004.
[7] S. de Lucas, J. Bartolomé, E. Rodríguez-Iñigo et al., "Distribution of hepatitis $\mathrm{C}$ virus infection in liver biopsies from children and adults with chronic hepatitis C," Journal of Medical Virology, vol. 64, no. 1, pp. 1-5, 2001.

[8] M. Chang, A. P. Marquardt, B. L. Wood et al., "in situ distribution of hepatitis $C$ virus replicative-intermediate RNA in hepatic tissue and its correlation with liver disease," Journal of Virology, vol. 74, no. 2, pp. 944-955, 2000.

[9] V. Agnello, G. Ábel, G. B. Knight, and E. Muchmore, "Detection of widespread hepatocyte infection in chronic hepatitis C," Hepatology, vol. 28, no. 2, pp. 573-584, 1998.

[10] D. Sansonno, V. Cornacchiulo, V. Racanelli, and F. Dammacco, "In situ simultaneous detection of hepatitis C virus RNA and hepatitis $\mathrm{C}$ virus-related antigens in hepatocellular carcinoma," Cancer, vol. 80, no. 1, pp. 22-33, 1997.

[11] S. W. Cho, S. G. Hwang, D. C. Han et al., "In situ detection of hepatitis $\mathrm{C}$ virus RNA in liver tissue using a digoxigenin-labeled probe created during a polymerase chain reaction," Journal of Medical Virology, vol. 48, no. 3, pp. 227-233, 1996.

[12] L. Tang, Y. Tanaka, N. Enomoto, F. Marumo, and C. Sato, "Detection of hepatitis C virus RNA in hepatocellular carcinoma by in situ hybridization," Cancer, vol. 76, no. 11, pp. 22112216, 1995.

[13] M. Gastaldi, A. Massacrier, R. Planells et al., "Detection by in situ hybridization of hepatitis $C$ virus positive and negative RNA strands using digoxigenin-labeled cRNA probes in human liver cells," Journal of Hepatology, vol. 23, no. 5, pp. 509-518, 1995.

[14] Y. Tanaka, N. Enomoto, S. Kojima et al., "Detection of hepatitis C virus RNA in the liver by in situ hybridization," Liver, vol. 13, no. 4, pp. 203-208, 1993.

[15] H. Nuriya, K. Inoue, T. Tanaka et al., "Detection of hepatitis B and $\mathrm{C}$ viruses in almost all hepatocytes by modified PCR-based in situ hybridization," Journal of Clinical Microbiology, vol. 48, no. 11, pp. 3843-3851, 2010.

[16] A. J. Alzahrani, P. J. Vallely, and R. F. T. McMahon, "Development of a novel nested in situ PCR-ISH method for detection of hepatitis C virus RNA in liver tissue," Journal of Virological Methods, vol. 99, no. 1-2, pp. 53-61, 2002.

[17] P. Biagini, L. Benkoel, F. Dodero et al., "Hepatitis C virus RNA detection by in situ RT-PCR in formalin-fixed paraffinembedded liver tissue. Comparison with serum and tissue results," Cellular and Molecular Biology, vol. 47, pp. OL167OL171, 2001.

[18] D. Bettinger, C. Mougin, B. Fouqué, B. Kantelip, J. P. Miguet, and M. Lab, "Direct in situ reverse transcriptase-linked polymerase chain reaction with biotinylated primers for the detection of hepatitis C virus RNA in liver biopsies," Journal of Clinical Virology, vol. 12, no. 3, pp. 233-241, 1999.

[19] F. M. Walker, M. Dazza, M. Dauge et al., "Detection and localization by in situ molecular biology techniques and immunohistochemistry of hepatitis $\mathrm{C}$ virus in livers of chronically infected patients," Journal of Histochemistry and Cytochemistry, vol. 46, no. 5, pp. 653-660, 1998.

[20] G. K. K. Lau, J. W. S. Fang, P. C. Wu, G. L. Davis, and J. Y. N. $\mathrm{Lau}$, "Detection of hepatitis $\mathrm{C}$ virus genome in formalin-fixed paraffin-embedded liver tissue by in situ reverse transcription polymerase chain reaction," Journal of Medical Virology, vol. 44, no. 4, pp. 406-409, 1994.

[21] C. Tateno, Y. Yoshizane, N. Saito et al., "Near completely humanized liver in mice shows human-type metabolic responses to drugs," American Journal of Pathology, vol. 165, no. 3, pp. 901912, 2004. 
[22] D. F. Mercer, D. E. Schiller, J. F. Elliott et al., "Hepatitis C virus replication in mice with chimeric human livers," Nature Medicine, vol. 7, no. 8, pp. 927-933, 2001.

[23] F. Ichida, "Histological grading criteria of chronic hepatitis: new Inuyama classification," in Proceedings of the 19th Inuyama Symposium, pp. 183-188, Chugai Igaku, 1996.

[24] K. Shiogama, H. Teramoto, Y. Morita et al., "Hepatitis C virus infection in a Japanese leprosy sanatorium for the past 67 years," Journal of Medical Virology, vol. 82, no. 4, pp. 556-561, 2010.

[25] L. A. Neely, S. Patel, J. Garver et al., "A single-molecule method for the quantitation of microRNA gene expression," Nature Methods, vol. 3, no. 1, pp. 41-46, 2006.

[26] W. P. Kloosterman, E. Wienholds, E. de Bruijn, S. Kauppinen, and R. H. A. Plasterk, "In situ detection of miRNAs in animal embryos using LNA-modified oligonucleotide probes," Nature Methods, vol. 3, no. 1, pp. 27-29, 2006.

[27] K. Kubota, A. Ohashi, H. Imachi, and H. Harada, "Improved in situ hybridization efficiency with locked-nucleic-acid-incorporated DNA probes," Applied and Environmental Microbiology, vol. 72, no. 8, pp. 5311-5317, 2006.

[28] R. Thomsen, P. S. Nielsen, and T. H. Jensen, "Dramatically improved RNA in situ hybridization signals using LNA-modified probes," RNA, vol. 11, no. 11, pp. 1745-1748, 2005.

[29] A. Válóczi, C. Hornyik, N. Varga, J. Burgyán, S. Kauppinen, and Z. Havelda, "Sensitive and specific detection of microRNAs by northern blot analysis using LNA-modified oligonucleotide probes," Nucleic Acids Research, vol. 32, no. 22, article el75, 2004.

[30] K. Sakurai, C. Furukawa, T. Haraguchi et al., "MicroRNAs miR199a-5p and $-3 p$ target the Brm subunit of SWI/SNF to generate a double-negative feedback loop in a variety of human cancers," Cancer Research, vol. 71, no. 5, pp. 1680-1689, 2011.

[31] N. Yamamichi, R. Shimomura, K. Inada et al., "Locked nucleic acid in situ hybridization analysis of miR-21 expression during colorectal cancer development," Clinical Cancer Research, vol. 15, no. 12, pp. 4009-4016, 2009.

[32] P. T. Nelson, D. A. Baldwin, W. P. Kloosterman, S. Kauppinen, R. H. A. Plasterk, and Z. Mourelatos, "RAKE and LNA-ISH reveal microRNA expression and localization in archival human brain," RNA, vol. 12, no. 2, pp. 187-191, 2006.

[33] Y. Liang, T. Shilagard, S. Xiao et al., "Visualizing hepatitis C virus infections in human liver by two-photon microscopy," Gastroenterology, vol. 137, no. 4, pp. 1448-1458, 2009.

[34] G. Li, K. Li, A. S. Lea et al., "In situ hybridization for the detection of hepatitis C virus RNA in human liver tissue," Journal of Viral Hepatitis, vol. 20, no. 3, pp. 183-192, 2013.

[35] T. Tanaka, K. Inoue, Y. Hayashi et al., "Virological significance of low-level hepatitis B virus infection in patients with hepatitis C virus associated liver disease," Journal of Medical Virology, vol. 72, no. 2, pp. 223-229, 2004.

[36] D. Revie and S. Z. Salahuddin, "Human cell types important for Hepatitis C Virus replication in vivo and in vitro. Old assertions and current evidence," Virology Journal, vol. 8, pp. 346-370, 2011. 


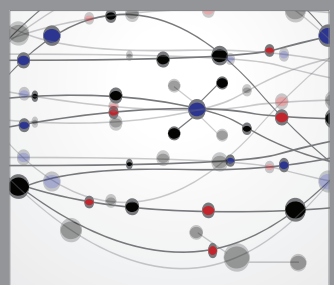

The Scientific World Journal
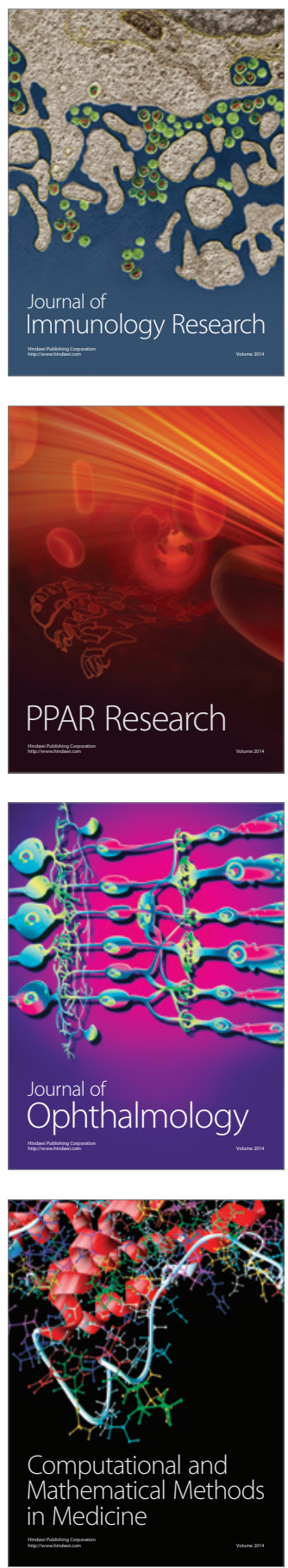

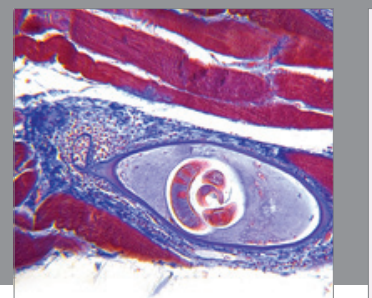

Gastroenterology

Research and Practice
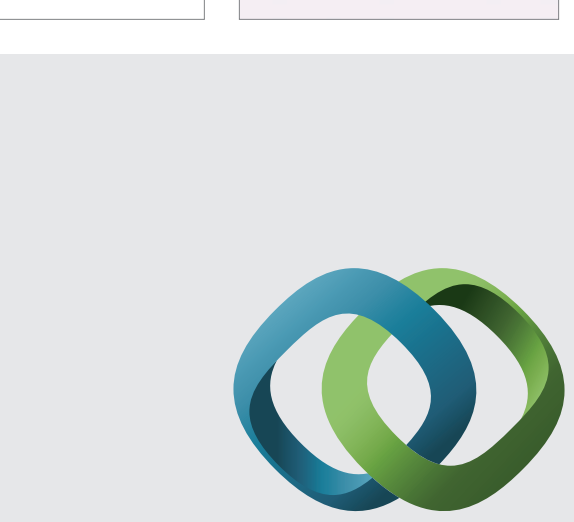

\section{Hindawi}

Submit your manuscripts at

http://www.hindawi.com
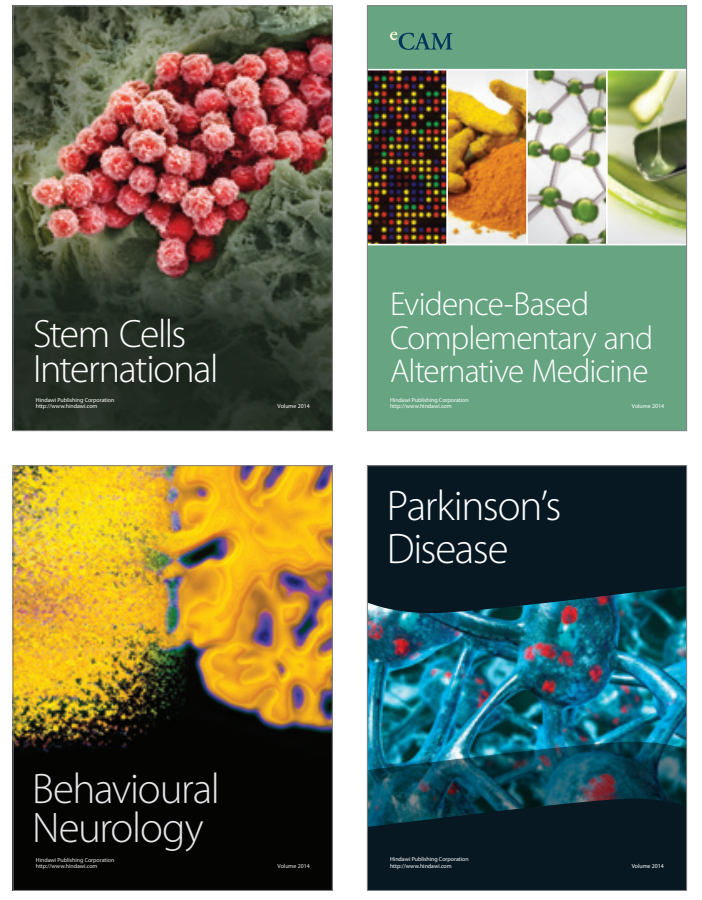
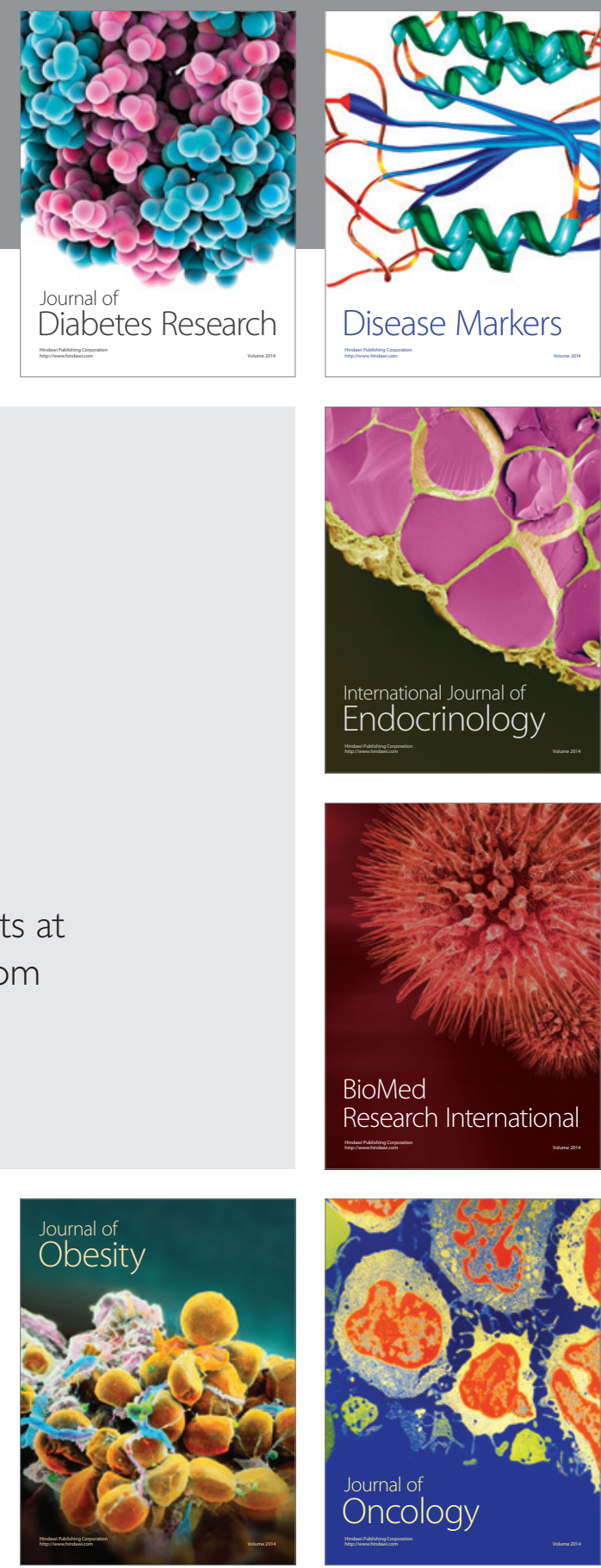

Disease Markers
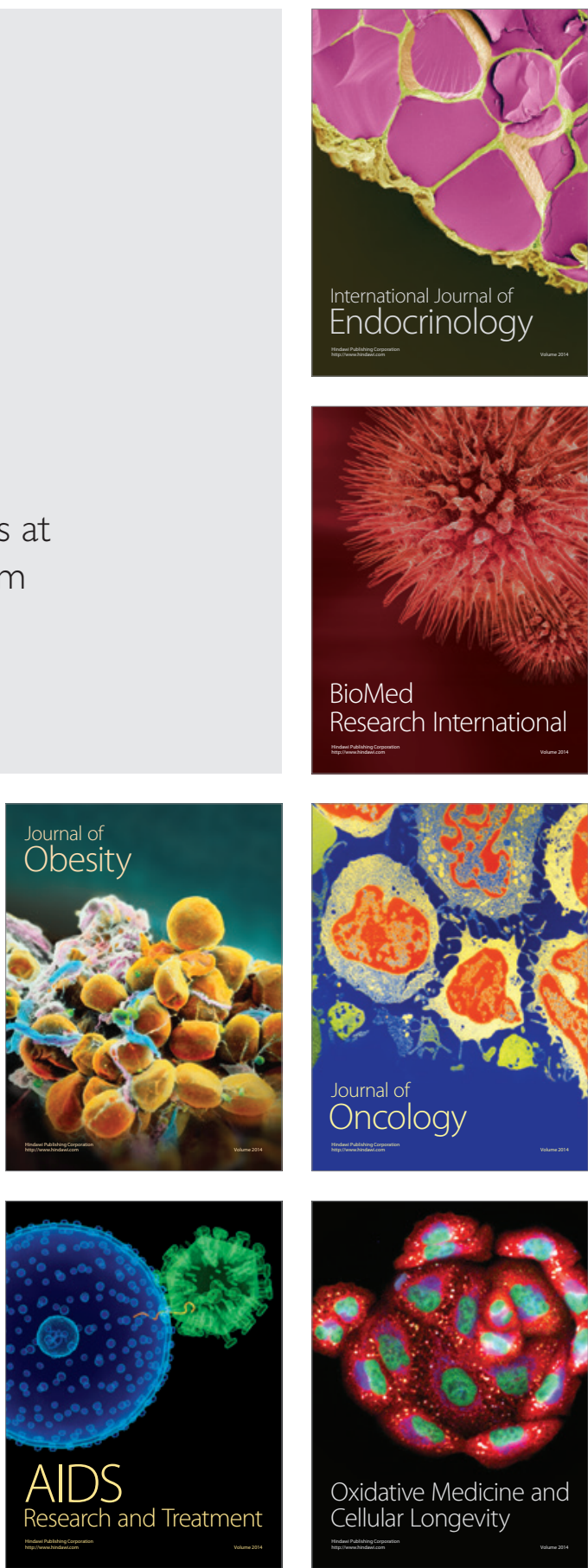